\title{
Reexamining 1-Gene Deletion \\ a-Thalassemia: Is the Silent Carrier of Clinical Significance?
}

\author{
Jeffrey R. Andolina
}

Department of Pediatrics, Golisano Children's Hospital, University of Rochester Medical Center, Rochester, NY, USA

$\alpha$-Thalassemia is considered to be the most common single-gene disorder in the world, and gene frequencies for abnormal alleles can reach up to $60-80 \%$ in some areas $[1,2]$. Located on chromosome 16 , there are 4 alleles for the $\alpha$-globin gene $(\alpha \alpha / \alpha \alpha)$, and there are variants including the silent carrier $(\alpha-/ \alpha \alpha)$, trait $(\alpha-/ \alpha-)$ or $(-/ \alpha \alpha)$, hemoglobin $\mathrm{H}$ disease $(-/ \alpha-)$, and hydrops fetalis $(-/-)$ [2]. Mutations may be deletions or point mutations. They cause decreased production of the a-globin chain, typically producing phenotypes ranging from asymptomatic to microcytic anemia and fetal demise. Historically, patients with $\alpha$-/a $\alpha$ have been thought to have normal hematologic parameters; the minimal decreases in hemoglobin and mean corpuscular volume (MCV) have been considered as being within the normal range [3]. However, data are sparse and formal testing of the silent carrier is limited.

In this issue of Acta Haematologica, Gilad et al. studied 192 children with genetically confirmed silent-carrier $\alpha$-thalassemia. The methodology was precise: all patients underwent complete testing for $\alpha$ - and $\beta$-thalassemia and iron deficiency as well as $\alpha$-globin gene sequencing. The study population was defined as those with the $-a^{3.7}$ deletion, which is the most common cause of silent carrier [1]; any patients with additional $\alpha$ - or $\beta$-thalassemia mutations or iron deficiency were excluded from the analysis. The study population was compared to age- and sexmatched control children.

Findings were surprising: children with the so-called silent carrier ( $-\alpha^{3.7}$ deletion) did not have normal hematologic parameters. In the population as a whole, $59 \%$ had hemoglobin $>1$ standard deviation (SD) below the mean, and $29 \%$ had hemoglobin $>2$ SDs below the mean. MCV and red blood cell (RBC) count values were even more striking: 76\% had MCV 2 SDs below the mean and 65\% had a RBC count 2 SDs above the mean. Hematologic parameters varied according to age: adolescent males with the silent carrier ( $-a^{3.7}$ deletion) had a mean hemoglobin of only $12.9 \mathrm{~g} / \mathrm{dL}$, statistically significantly below the control mean hemoglobin values of 14.4 and $15.4 \mathrm{~g} / \mathrm{dL}$. Older children were also much more likely to have significant abnormalities: $100 \%$ of children aged $\geq 6$ years had an MCV $>2$ SDs below the mean.

The main limitation to the data is that all patients were initially screened for a referral of microcytosis, so there is a possibility of referral bias. Still, the hematologic differences in children with silent carrier $\left(-\alpha^{3.7}\right.$ deletion $)$ and normal controls were quite impressive. karger@karger.com www.karger.com/aha

(c) 2019 S. Karger AG, Basel

Karger"
Jeffrey R. Andolina, MD, MS

Department of Pediatrics, Golisano Children's Hospital University of Rochester Medical Center 601 Elmwood Ave, Box 777, Rochester, NY 14642 (USA)

E-Mail Jeffrey_andolina@ urmc.rochester.edu 
Historically, many children with borderline hemoglobin and MCV values, in the absence of other etiologies, would be assumed to have silent-carrier $\alpha$-thalassemia. However, today, genetic testing is readily available and relatively inexpensive. One approach for evaluating $\alpha$ thalassemia variants includes testing for 7 common deletions $\left(-\alpha^{3.7},-\alpha^{4.2},-\alpha^{20.5},-S E A,-M E D,-F I L\right.$, and $-T H A I$; ARUP Laboratories). Confirming a diagnosis of silentcarrier or trait $\alpha$-thalassemia can be beneficial for patients, and ensures that they are not mislabeled as having iron deficiency or other competing diagnoses. Furthermore, in populations with many deletions or mutations, confirming the $\alpha$-thalassemia genetic status can be helpful for future parental genetic counseling.

Further research can help to clarify the variant genotypes and phenotypes of children with silent-carrier $\alpha$-thalassemia. Population-based data may also help to better define the hematologic parameters of silent-carrier a-thalassemia, which likely vary by mutation and possibly according to race or ethnicity. Finally, a name change may be in order, as the hematologic values of children with silent carrier seem to be anything but silent.

\section{Disclosure Statement}

There are no conflicts of interest to disclose.

\section{References}

1 Higgs DR, Vickers MA, Wilkie AO, Pretorius IM, Jarman AP, Weatherall DJ. A review of the molecular genetics of the human alpha-globin gene cluster. Blood. 1989 Apr;73(5):1081-104.

2 Piel FB, Weatherall DJ. The $\alpha$-thalassemias. N Engl J Med. 2014 Nov; 371(20):1908-16.

3 Galanello R, Cao A. Gene test review. Alpha-thalassemia. Genet Med. $2011 \mathrm{Feb} ; 13(2): 83-8$. 